Politisches Denken · Jahrbuch 1995/96 
In Verbindung mit der

Deutschen Gesellschaft zur Erforschung des Politischen Denkens.

Redaktionsanschriften:

Prof. Dr. Volker Gerhardt, Institut für Philosophie, Humboldt Universität Berlin, Unter den Linden 6, 10099 Berlin

Prof. Dr. Henning Ottmann

Geschwister-Scholl-Institut für Politische Wissenschaft, Universität München, Ludwigstr. 10, 80539 München

Wissenschaftlicher Beirat:

Karl Dietrich Bracher (Bonn), Reinhard Brandt (Marburg), Maurice Cranston (London) ( $\dagger$ ), John Dunn (Cambridge), Iring Fetscher (Frankfurt), Klaus Hartmann (Tübingen) ( $\dagger$ ), Wilhelm Hennis (Freiburg), Dieter Henrich (München), Otfried Höffe (Tübingen), Hasso Hofmann (Berlin), Nikolaus Lobkowicz (Eichstätt), Hermann Lübbe (Zürich), Odo Marquard (Gießen), Kenneth Minogue (London), Michael Oakeshott (London) (†), J. G. A. Pocock (Hopkins University), Melvin Richter (New York), Quentin Skinner (Cambridge), Michael Stolleis (Frankfurt) 


\title{
Politisches Denken Jahrbuch 1995/96
}

\author{
Herausgegeben von \\ Karl Graf Ballestrem, Volker Gerhardt, \\ Henning Ottmann und Martyn P. Thompson
}

Verlag J. B. Metzler Stuttgart $\cdot$ Weimar 
Die Deutsche Bibliothek - CIP-Einheitsaufnahme

Politisches Denken : Jahrbuch ...;

Jahrbuch der Deutschen Gesellschaft zur Erforschung des Politischen Denkens. Stuttgart/Weimar: Metzler.

Erscheint jährlich. - Aufnahme nach 1991 (1992)

ISSN 0942-2307

1991 (1992) -

Dieses Werk einschließlich aller seiner Teile ist urheberrechtlich geschützt.

Jede Verwertung außerhalb der engen Grenzen des Urheberrechtsgesetzes ist ohne Zustimmung des Verlages unzulässig und strafbar.

Das gilt insbesondere für Vervielfältigungen, Übersetzungen,

Mikroverfilmungen und die Einspeicherung und Verarbeitung in elektronischen Systemen.

ISSN 0942-2307

ISBN 978-3-476-01385-9

ISBN 978-3-476-03633-9 (eBook)

DOI 10.1007/978-3-476-03633-9

(C) 1996 Springer-Verlag GmbH Deutschland

Ursprünglich erschienen bei J.B.Metzlersche Verlagsbuchhandlung

und Carl Ernst Poeschel Verlag GmbH in Stuttgart 1996 


\title{
Inhalt
}

\author{
Henning Ottmann \\ In eigener Sache: Politisches Denken. \\ Oder: Warum der Begriff "Politisches Denken" \\ konkurrierenden Begriffen vorzuziehen ist
}

1

KARIN WIELAND

Die Politik des Fürstendieners.

Baldesar Castiglione und "Das Buch vom Hofmann"

9

Thomas Rentsch

Die Konstitution der Konstitution.

Rechtsphilosophische Bemerkungen zur Legitimation des Grundgesetzes

29

HermanN KLenNer

Über Vorverständnisse von Recht in neuerer Zeit

47

Horst Firsching

Zur Geschichte und Problematik einer `Soziologie der Moral

57

JOHANNES Weiß

Marx oder Weber?

73

Siegfried LANDShUt

Das Wesen der modernen Gesellschaft nach Karl Marx und Max Weber 85

IRING FETSCHER

Hannah Arendt über "produktive und unproduktive Arbeit" bei Adam Smith und Karl Marx. Eine Richtigstellung 
Sehnsucht nach dem ganz Anderen. Annäherungen an Max Horkheimer 125

\author{
Olaf Asbach
}

Politik und Frieden beim Abbé de Saint-Pierre.

Erinnerungen an einen (fast) vergessenen Klassiker der politischen Philosophie 133

\title{
Georg Geismann \\ Kant on Eternal Peace
}

165

\section{Hector Wittwer}

Transzendentale Eschatologie und Kritische Geschichtsbetrachtung bei Kant. Die Zweideutigkeit des Ideals vom Ewigen Frieden

179

\section{Wolfgang Kersting}

Globale Rechtsordnung oder weltweite Verteilungsgerechtigkeit? Über den systematischen Grundriß einer politischen Philosophie der internationalen Beziehungen

197

Thomas Julian Page

Stein and Tocqueville in Metropolis. Towards a Contemporary

Theory of Local Citizenship in Germany and America 247

\section{JÜrgen GebHARDT}

Zwischen Wissenschaft und Religion

Zur intellektuellen Biographie E. Voegelins in den 30er Jahren 283

\section{Diskussion}

\section{Wilhelm Hennis}

Max Webers » Vorbericht für eine Erhebung zur Soziologie des Zeitungswesens «. Einführung und Text 
Udo Tietz

Die schmutzigen Hände. Schuld, Verantwortung und der schwierige Umgang mit unserer Geschichte

323

\section{Rezensionen}

\section{Christoph Quarch}

Die Geburt des Politischen und der Geist der Tragödie.

Christian Meier erzählt den politischen Mythos Europas

Über: Christian Meier, Athen. Ein Neubeginn der Weltgeschichte

343

Gerald Rosenberger

Eine Bilanz ohne Aktivseite

Über: Klaus Hornung, Das totalitäre Zeitalter. Bilanz des 20. Jahrhunderts 349

\section{Uwe Justus Wenzel}

Das Recht der Philosophie und die Philosophie des Menschenrechts

Über: Walter Schweidler, Geistesmacht und Menschenrecht.

Der Universalanspruch der Menschenrechte und das Problem der Ersten Philosophie

353

\section{Veit Friemert}

Eine Neuvermessung des Kontraktualismus

Über: Wolfgang Kersting, Die politische Philosophie des Gesellschaftsvertrags 357

\section{SiegFried WeICHLEIN}

Europäische Geschichte in Nationalgeschichten verstrickt Über: Hagen Schulze, Staat und Nation in der europäischen Geschichte

367

\section{Reinhard Mehring}

Die Normalität der Normativität einer Republik Über: Jürgen Habermas, Die Normalität einer Berliner Republik 